\title{
The involvement of cancer patients in the four stages of decision-making preceding continuous sedation until death: A qualitative study
}

Palliative Medicine

$1-10$

(C) The Author(s) 2018

Reprints and permissions:

sagepub.co.uk/journalsPermissions.nav DOI: I0.1 I77/02692।63।8770342 journals.sagepub.com/home/pmj

(S)AGE

\author{
Lenzo Robijn 1,2@, Jane Seymour ${ }^{3}$, Luc Deliens ${ }^{1,2}$, Ida Korfage ${ }^{4}$, \\ Jayne Brown ${ }^{5,6}$, Peter Pype ${ }^{1,7}$, Agnes Van Der Heide, \\ Kenneth Chambaere ${ }^{1,2}$ and Judith Rietjens ${ }^{4}$; on behalf of the \\ UNBIASED consortium
}

\begin{abstract}
Background: Involving patients in decision-making is considered to be particularly appropriate towards the end of life. Professional guidelines emphasize that the decision to initiate continuous sedation should be made in accordance with the wishes of the dying person and be preceded by their consent.

Aim: To describe the decision-making process preceding continuous sedation until death with particular attention to the involvement of the person who is dying.

Design: Qualitative case studies using interviews.

Setting/participants: Interviews with 26 physicians, 30 nurses and 24 relatives caring for 24 patients with cancer who received continuous sedation until death in Belgium, the United Kingdom and the Netherlands.

Results: We distinguished four stages of decision-making: initiation, information exchange, deliberation and the decision to start continuous sedation until death. There was wide variation in the role the patient had in the decision-making process. At one end of the spectrum (mostly in the United Kingdom), the physician discussed the possible use of sedation with the patient, but took the decision themselves. At the other end (mostly in Belgium and the Netherlands), the patient initiated the conversation and the physician's role was largely limited to evaluating if and when the medical criteria were met.

Conclusion: Decision-making about continuous sedation until death goes through four stages and the involvement of the patient in the decision-making varies. Acknowledging the potential sensitivity of raising the issue of end-of-life sedation, we recommend building into clinical practice regular opportunities to discuss the goals and preferences of the person who is dying for their future medical treatment and care.
\end{abstract}

\section{Keywords}

Patient participation, decision-making, patient-centred care, continuous sedation until death, palliative sedation, qualitative research

\section{What is already known about the topic?}

- Involving patients in making decisions about their own treatment and care has been recognized as a cornerstone of person-centred care and is considered to be particularly appropriate towards the end of life because end-of-life decisions are probably even more preference-sensitive.

'End-of-Life Care Research Group, Vrije Universiteit Brussel (VUB) \& Ghent University, Brussels, Belgium

${ }^{2}$ Department of Internal Medicine, Ghent University, Ghent, Belgium

${ }^{3}$ The School of Nursing and Midwifery, The University of Sheffield,

Sheffield, UK

${ }^{4}$ Department of Public Health, Erasmus University Medical Centre (Erasmus MC), Rotterdam, The Netherlands

${ }^{5}$ School of Nursing and Midwifery, De Montfort University, Leicester, UK
${ }^{6}$ Centre for the Promotion of Excellence in Palliative Care, De Montfort University, Leicester, UK

${ }^{7}$ Department of Family Medicine and Primary Health Care, Ghent University, Ghent, Belgium

Corresponding author: Lenzo Robijn, End-of-Life Care Research Group, Vrije Universiteit Brussel (VUB) \& Ghent University, Laarbeeklaan 103, 1090 Brussels, Belgium. Email: Lenzo.Robijn@vub.be 
- Up to now, most studies on the involvement of patients in treatment decision-making are conducted in a curative setting, where patients often have to choose between two treatments that have both proven to be effective. However, it is not known to what extent the choices and preferences of patients are taken into account in end-of-life decision-making when cure is no longer possible.

\section{What this paper adds?}

- This study enhances understanding in end-of-life decision-making by making use of Charles et al.'s model of treatment decision-making that allowed us to scrutinize the different phases of decision-making and apply them to the process of continuous sedation.

- Decision-making about continuous sedation until death goes through four stages and the use of sedation is preceded by two types of decision: the decision about whether to use sedation and the decision about when to start sedation.

- Although the overarching goal of continuous sedation at the end of life was similar in all cases, there was considerable variation in the timing and the role played by the patient in the decision-making in the countries studied.

\section{Implications for practice, theory or policy}

- Our findings point to the need to regularly discuss with people who are dying their goals and preferences regarding future medical care and treatment.

- Future research should further unravel how patient preferences are elicited in actual encounters and what consequences this may have for the chances of the person who is dying participating in decision-making about the ending of their own life.

\section{Introduction}

Patient participation in decision-making is considered to be particularly appropriate towards the end of life because end-of-life decisions are often preference-sensitive. ${ }^{1-4}$ Studies have suggested that although a majority of people with limited life expectancy prefer a shared or active role in decision-making, their physicians and those close them are frequently unaware of their preferences. ${ }^{5-7}$ One of the most debated end-of-life practices is palliative sedation, particularly when it is used continuously until death. ${ }^{8-11}$ It entails the use of medication intended to induce a state of decreased consciousness until death to relieve the burden of symptoms that cannot be controlled adequately by conventional palliative treatment. ${ }^{12,13}$ Guidelines emphasize that the decision to initiate sedation should be made in accordance with the wishes of the patient and be preceded by their consent or the consent of a surrogate decisionmaker if they lack decision-making capacity. ${ }^{12,14,15}$ Empirical studies have shown, however, that patient consent is not always obtained or sought. ${ }^{16,17}$

Previous research has shown that continuous sedation until death is practiced differently in different countries. The international UNBIASED study ${ }^{18,19}$ showed that in the United Kingdom, the use of sedation is typically described as a gradual process involving increasing the dose in the context of symptom management, rather than as a deliberate planned event. In contrast, Belgian clinicians predominantly described it as an act of deep sedation from the start, emphasizing the importance of it being in response to a patient's request. Dutch clinicians emphasized that its use was a medical decision informed by the patient's wishes after establishing the presence of a refractory symptom. This suggests that the practice of continuous sedation, the decision-making leading up to continuous sedation, and the extent to which the choices and preferences of patients are taken into account, may differ between countries. This study describes the decision-making process surrounding continuous sedation at the end of life in Belgium, the Netherlands and the United Kingdom, with particular attention to the role of patients.

\section{Methods}

This study is part of the UNBIASED project undertaken in the United Kingdom (UK), the Netherlands (NL) and Belgium (BE) and involved in-depth interviews with physicians, nurses and decedents' relatives. ${ }^{18,20-23}$ The study was approved by research ethics committees as follows:

- United Kingdom: Leicestershire, Northampton and Rutland Research Ethics Committee 1, 10/H0406/57

- Belgium: Ghent University Hospital Ethics Committee, B670201010174

- The Netherlands: Erasmus MC Medical Ethical Research Committee, NL33327.078.10, v03.

\section{Settings}

To enable maximum variation in the cases studied, we explored the care of cancer patients who died in hospitals (oncology wards), palliative care unit (PCU) (in Belgium) 
Table I. Charles et al.'s ${ }^{24}$ model of treatment decision-making.

\begin{tabular}{llll}
\hline & Paternalistic & Shared decision-making & Informed \\
\hline Information exchange & $\begin{array}{l}\text { One-way: from doctor to } \\
\text { patient, minimum necessary for } \\
\text { informed consent }\end{array}$ & $\begin{array}{l}\text { Two-way: doctor provides all medical } \\
\text { information needed for decision- } \\
\text { making, patient provides information } \\
\text { about his or her preferences }\end{array}$ & $\begin{array}{l}\text { One-way (largely): from } \\
\text { doctor to patient, all medical } \\
\text { information needed for } \\
\text { decision-making }\end{array}$ \\
Deliberation & $\begin{array}{l}\text { Physician alone, or with other } \\
\text { physicians } \\
\text { Decision }\end{array}$ & $\begin{array}{l}\text { Physician and patient (plus potential } \\
\text { others) }\end{array}$ & Patient (plus potential others) \\
\hline
\end{tabular}

or hospices (in the UK and the Netherlands), and in the community (at home).

\section{Participants and inclusion criteria for decedents}

In all countries, senior clinical staff members identified eligible decedents: patients aged over 18 who had died of cancer and to whom sedating medications were administered continuously with the intention of decreasing awareness to alleviate otherwise uncontrollable symptoms (either physical or psychological/existential), and for whom the sedation was in place at the time of death. Nurses and physicians were invited to take part if they had been closely involved in the care of these patients and were interviewed about not more than three cases. If more than one physician or nurse was involved, all were interviewed where possible. Relatives were invited to participate via a letter and information sheet sent on behalf of the research team by the patient's physician. Interviews took place as soon as possible after death, that is, within 12 weeks, to maximize recall. This article involves all complete cases (with at least one physician, one nurse and one relative interviewed) in order to obtain a comprehensive insight into the decision-making process.

\section{Procedures}

Interviews were semi-structured using an aide mémoire. Interviews focussed on recollections of the care of the decedent, reasons for the use of sedation, its implementation and decision-making. Each participant gave written informed consent before taken part. The interviews were undertaken by trained interviewers and lasted approximately $60 \mathrm{~min}$. Physicians and nurses could use the patient records if necessary to support them in their recollections but were asked to provide relevant information about the case in an anonymous manner. Interviews were audio recorded, transcribed and translated as required. Data collection was completed by the end of 2012 .

\section{Analysis}

Qualitative analysis software (NVIVO 11) was used to organize the data. The coding procedure of the interviews strictly followed the methods of qualitative content analysis. A combined model of inductive and deductive coding was used, where deductive coding was based on Charles et al.'s ${ }^{24}$ key model of treatment decision-making (Table 1). Qualitative analysis software (NVIVO 11) was used to organize the data. Three researchers (L.R., K.C. and J.R.) independently analysed a first set of transcripts for concepts that were directly linked to the patient's preferences for sedation and their role in decision-making. The codes were compared and discrepancies were discussed until agreement was reached. A coding tree was developed by L.R., K.C., L.D. and J.R. and agreed upon with all coauthors. All interviews were coded and quotes were selected on the basis of their being representative of the wider data and approved by all researchers. We followed the 'Consolidation Criteria for Reporting Qualitative Studies' (COREQ) guidelines to ensure rigour in our research. ${ }^{25}$

\section{Results}

We studied all 24 complete patient cases (7 UK; $7 \mathrm{BE}$; 10 $\mathrm{NL}$ ), involving interviews with 26 physicians ( $9 \mathrm{UK} ; 7$ $\mathrm{BE} ; 10 \mathrm{NL}), 30$ nurses (10 UK; $10 \mathrm{BE} ; 10 \mathrm{NL}$ ) and 24 relatives (7 UK; $7 \mathrm{BE} ; 10 \mathrm{NL}$ ). Table 2 provides an overview of the characteristics of the patients. Table 3 gives characteristics of the interviewees, showing that the majority of the clinicians ( 36 out of 56) were palliative care or hospice practitioners. Besides the three stages of decision-making as described in the model of Charles et al. ${ }^{24}$ (Table 1), the initiation phase was added as it was important to understand who initiated or raised the possibility of sedation. We were therefore able to distinguish four stages of decisionmaking: (1) the initiation phase to understand who initiated or raised the possibility of sedation; (2) the exchange of all necessary information; (3) the deliberation phase in which it was decided to use continuous sedation when necessary and (4) the decision to actually begin it. Table 4 gives an overview of the characteristics of the decisionmaking process in all three countries.

\section{Initiating the conversation}

The initiation phase appeared to be an interplay between the medical team and the patient and could best 
Table 2. Characteristics of patients.

\begin{tabular}{|c|c|c|c|c|}
\hline Characteristics & United Kingdom & Belgium & The Netherlands & Total \\
\hline Number of cases & 7 & 7 & 10 & 24 \\
\hline \multicolumn{5}{|l|}{ Age (years) } \\
\hline$<50$ & - & I & - & I \\
\hline $51-60$ & 2 & 2 & 2 & 6 \\
\hline $6 I-70$ & 3 & - & 2 & 5 \\
\hline $7 I-80$ & 2 & 3 & 5 & 10 \\
\hline $80+$ & - & I & I & 2 \\
\hline \multicolumn{5}{|l|}{ Gender } \\
\hline Male & 5 & 4 & 6 & 15 \\
\hline Female & 2 & 3 & 4 & 9 \\
\hline \multicolumn{5}{|l|}{ Diagnosis } \\
\hline Adenocarcinoma & - & - & I & 1 \\
\hline Abdominal/stomach & - & - & I & 1 \\
\hline Bladder & I & - & - & 1 \\
\hline Colon & - & I & - & 1 \\
\hline Facial maxillary & I & - & - & 1 \\
\hline Gall bladder & I & - & - & 1 \\
\hline Oesophageal & - & - & I & 1 \\
\hline Leukaemia/myelofibrosis/myeloma & - & 2 & - & 2 \\
\hline Lung/mesothelioma & - & I & 3 & 4 \\
\hline Melanoma & - & I & I & 2 \\
\hline Pancreatic & I & - & I & 2 \\
\hline Peritoneal & I & I & - & 2 \\
\hline Prostate & I & - & I & 2 \\
\hline Renal/hypernephroma & I & I & - & 2 \\
\hline Unknown & - & - & 1 & 1 \\
\hline \multicolumn{5}{|l|}{ Care setting } \\
\hline Home & 3 & 3 & 4 & 10 \\
\hline Hospital & - & 2 & 3 & 5 \\
\hline Palliative care unit (BE)/hospice (UK/NL) & 4 & 2 & 3 & 9 \\
\hline
\end{tabular}

be understood as a continuum with, at the extremities, the initiative driven predominantly either by the patient or by the physician. When patients initiated it, they did so by indicating that their suffering had become unbearable and they no longer wanted to, or could, continue their treatment or even their life. Patients expressed this using such phrases as 'I am ready to die', 'I have had enough', 'I can no longer bear it' or 'I am done'. Others expressed more explicit requests to 'go to sleep' or to 'no longer wake up'. When a patient was no longer able to communicate, in all countries it was often the family who expressed what they believed to be the patient's preferences.

In Belgium and the Netherlands, some patients requested euthanasia. This was often the starting point of a conversation about end-of-life preferences and the possible use of sedation:

We never spoke about the final stage of life and I found it difficult to start talking about it. And then two weeks before the end, he was so tired, he said, I don't want this, I cannot go on, I want euthanasia. Well a week passed and then Dr X came here, and then he discussed palliative sedation, you go to sleep and you aren't aware of anything. Well only his thumb went up ... (The Netherlands, Case 12, Home, Relative)

In other situations, physicians initiated the conversation about the possible use of sedation, for instance when an acute exacerbation of symptoms that could not be managed in any other way was expected. During the course of the disease, physicians repeatedly discussed with the patient whether they were 'still okay' or if they could 'still bear the pain'. Nurses also had an important role in initiating discussion about the possible use of sedation:

So then the option, palliative sedation actually became real, for me because it was obvious this is a major medical problem which can't be solved in another way anymore and [...] the life expectancy suddenly becomes very short. He was in pain and he constantly sick, so he met the criteria of palliative sedation. And that possibility was therefore discussed at that moment. [...] They always were very difficult conversations because he did not really want to address those really big issues. (The Netherlands, Case 36, Community, Physician) 
Table 3. Characteristics of physicians, nurses and relatives.

\begin{tabular}{|c|c|c|c|c|c|c|c|c|c|}
\hline \multirow{2}{*}{$\begin{array}{l}\text { Characteristics } \\
\text { Country }\end{array}$} & \multicolumn{3}{|c|}{ Physicians $(n=26)$} & \multicolumn{3}{|c|}{ Nurses $(n=30)$} & \multicolumn{3}{|c|}{ Relatives $(n=24)$} \\
\hline & $\begin{array}{l}\text { UK } \\
(n=9)\end{array}$ & $\operatorname{BE}(n=7)$ & $N L(n=10)$ & $\begin{array}{l}\text { UK } \\
(n=10)\end{array}$ & $\operatorname{BE}(n=10)$ & $\begin{array}{l}\mathrm{NL} \\
(\mathrm{n}=10)\end{array}$ & UK $(n=7)$ & $\mathrm{BE}(n=7)$ & $N L(n=10)$ \\
\hline Age (years) & & & & & & & N/A & $N / A$ & N/A \\
\hline$<40$ & 5 & 2 & 3 & 1 & 4 & 6 & & & \\
\hline $40-50$ & - & 3 & I & 3 & 2 & 2 & & & \\
\hline $5 I-60$ & - & 2 & 5 & I & 4 & 2 & & & \\
\hline $60+$ & - & - & I & 1 & - & - & & & \\
\hline Not stated & 4 & - & - & 4 & - & - & & & \\
\hline \multicolumn{10}{|l|}{ Gender } \\
\hline Male & 6 & 4 & 9 & - & 1 & I & 1 & 4 & 2 \\
\hline Female & 3 & 3 & 1 & 10 & 9 & 9 & 6 & 3 & 8 \\
\hline \multicolumn{10}{|l|}{ Specialism } \\
\hline Primary care & 4 & 2 & 4 & 1 & 2 & 1 & N/A & N/A & N/A \\
\hline $\begin{array}{l}\text { Palliative home } \\
\text { care team }\end{array}$ & - & 1 & - & 2 & 3 & 3 & & & \\
\hline $\begin{array}{l}\text { Hospital } \\
\text { oncology ward }\end{array}$ & - & - & 2 & - & 2 & 2 & & & \\
\hline $\begin{array}{l}\text { Palliative care } \\
\text { unit/hospice } \\
\text { care }\end{array}$ & 5 & 4 & 4 & 7 & 3 & 4 & & & \\
\hline $\begin{array}{l}\text { Nature of } \\
\text { relationship with } \\
\text { patient }\end{array}$ & $N / A$ & $N / A$ & N/A & $\mathrm{N} / \mathrm{A}$ & N/A & N/A & & & \\
\hline Partner & & & & & & & 4 & 4 & 6 \\
\hline Child & & & & & & & 3 & 2 & 2 \\
\hline Sibling & & & & & & & - & I & I \\
\hline Parent & & & & & & & - & - & 1 \\
\hline
\end{tabular}

UK: United Kingdom; BE: Belgium; NL: The Netherlands; N/A: not applicable.

More than one could have been interviewed. Results from the relatives were identified by the relative that was identified by the physician as being the most involved.

\section{Information exchange}

Once the conversation was initiated, it was usually the physician who summarized the situation and provided information to the patient and family. We distinguished two types of decision-making. In the first, mainly in the Netherlands and Belgium, the physician had a predominantly informative role, informing the patient about their disease progression and the possibility of using sedation and the circumstances under which it could be used. They then either hoped to come to a shared decision by further exploring the preferences of the patient or they left it to the patient to make an informed decision themselves. Where desired, these physicians gave advice but during the interviews they mainly stressed the importance of responding to patient's specific requests and wishes or the fact that the final choice should lie with the patient, provided that the clinical conditions were fulfilled:

He pretended for a long time that everything was alright. But certainly the sedation was discussed towards the end, because what I can remember is that we did make the offer to him, like, to go to sleep, at a time when it would be really untenable.

(The Netherlands, Case 21, Hospice, Physician)
In the second type of situation, mainly in the UK, the physician took the lead by proposing the possible use of palliative sedation to control symptoms and to relieve terminal suffering. In these cases, they aimed mainly to provide all the necessary information and then eventually to obtain the informed consent of the patient and/or the family:

Things were progressing ... and at that time, he had got his pump in and they suggested, 'Well, we'll give him this drug that will help to calm him down, that he's not afraid ... that he can rest easy and he doesn't get bad dreams and that sort of things'. (UK, Case 1, Community, Relative)

\section{Deliberation and the decision to use continuous sedation until death}

In all three countries, the possible use of sedation was usually discussed between the person who was dying, those close to them and the professional caregivers, which ultimately led to the consent and/or decision to use sedation. In some cases, there were difficulties in coming to a decision. This happened particularly in situations where patients or 
Table 4. Characteristics of the decision-making process in the studied countries.

\begin{tabular}{|c|c|c|c|}
\hline Stages & United Kingdom (UK) & The Netherlands & Belgium \\
\hline $\begin{array}{l}\text { I. Initiating the } \\
\text { conversation }\end{array}$ & $\begin{array}{l}\text { A continuum with the initiative } \\
\text { driven either by the patient or by } \\
\text { the physician }\end{array}$ & $\begin{array}{l}\text { A continuum with the initiative } \\
\text { driven either by the patient or } \\
\text { by the physician. Euthanasia } \\
\text { was often the starting point of } \\
\text { a conversation about end-of-life } \\
\text { preferences and the possible use } \\
\text { of sedation }\end{array}$ & $\begin{array}{l}\text { A continuum with the initiative } \\
\text { driven either by the patient or } \\
\text { by the physician. Euthanasia } \\
\text { was often the starting point of } \\
\text { a conversation about end-of-life } \\
\text { preferences and the possible use } \\
\text { of sedation }\end{array}$ \\
\hline $\begin{array}{l}\text { 2. Information } \\
\text { exchange }\end{array}$ & $\begin{array}{l}\text { The physician usually took the } \\
\text { lead providing all the necessary } \\
\text { information to obtain informed } \\
\text { consent of the patient and/or } \\
\text { relatives }\end{array}$ & $\begin{array}{l}\text { The physician had rather an } \\
\text { informative role, providing all } \\
\text { medical information needed for } \\
\text { decision-making, hoping to come } \\
\text { to a shared decision by further } \\
\text { exploring patient preferences }\end{array}$ & $\begin{array}{l}\text { The physician mainly had an } \\
\text { informative role, providing all } \\
\text { medical information needed for } \\
\text { decision-making, hoping to come } \\
\text { to a shared decision by further } \\
\text { exploring patient preferences }\end{array}$ \\
\hline $\begin{array}{l}\text { 3. Deliberation and } \\
\text { the decision to use } \\
\text { continuous sedation } \\
\text { until death }\end{array}$ & $\begin{array}{l}\text { Usually discussed between the } \\
\text { patient and those close to them. } \\
\text { In case of disagreement, physician } \\
\text { followed the patient's wishes }\end{array}$ & $\begin{array}{l}\text { Usually discussed between the } \\
\text { patient and those close to them. } \\
\text { In case of disagreement, physician } \\
\text { followed the patient's wishes }\end{array}$ & $\begin{array}{l}\text { Usually discussed between the } \\
\text { patient and those close to them. } \\
\text { In case of disagreement, physician } \\
\text { followed the patient's wishes }\end{array}$ \\
\hline $\begin{array}{l}\text { 4. Decision phase - the } \\
\text { moment to start } \\
\text { continuous sedation } \\
\text { until death }\end{array}$ & $\begin{array}{l}\text { A gradual progression without a } \\
\text { particular moment of decision- } \\
\text { making }\end{array}$ & $\begin{array}{l}\text { Generally, a medical decision that } \\
\text { physicians could take only if they } \\
\text { felt that it was inevitable }\end{array}$ & $\begin{array}{l}\text { When competent, in most cases } \\
\text { either patient or the medical staff } \\
\text { who took the final decision to } \\
\text { start. When no longer competent, } \\
\text { either family or the medical staff }\end{array}$ \\
\hline
\end{tabular}

their relatives 'still had to get used to the idea' or 'were not yet ready to say goodbye' or 'there was basically no time at all to cope with any of it'. For example, although one patient (UK, case 2, Hospice) was according to the physician clearly in the dying phase, his wife was 'really struggling' and worried about him being 'knocked out':

The day that he got transferred to (Hospice), so while he was still on the oncology ward, erm, his wife was not coping, she was devastated at the idea that we were gonna knock him out, or put him to sleep, and that she won't be able to speak to him again. [...] And I can understand that question coming through. However, it became obvious once we'd assessed him later on that actually he was needing that. And her distress was understandable and was difficult, but I think, by the time I saw him, I think she'd probably changed to, you know, wanting us to do more for him ... (UK, Case 2, Hospice, Physician)

In Belgium and the Netherlands, the discussion sometimes specifically focussed on the 'choice' between palliative sedation and euthanasia:

It was actually a completely chosen path and we knew where we were going. It depended only from how the patient then decided that they would evolve from 'here I go to the euthanasia, or there I will go to palliative sedation'. And I had well informed her about it and she has consciously made that choice. (Belgium, Case 11, Community, Physician)

In cases of disagreement between patients and their relatives, physicians and nurses attempted to reconcile the two views. If this eventually proved impossible, physicians emphasized the importance of following the patient's wishes since 'they are the ones with pain'.

\section{Decision phase - the moment to start continuous sedation until death}

The involvement of patients in this phase was dependent whether the person who was dying was considered to have the capacity to take part in the final stages of the decisionmaking process or not. When competent, it was either they or the medical staff who took the final decision to begin palliative sedation. Patients in Belgium and the Netherlands indicated their readiness for the use of sedation in the later phases using phrases such as 'it should happen today' and 'it is enough for me now':

And the physician said 'but we cannot decide it, that is up to you to decide when you want it. And my dad said 'ah I may decide that?' 'Yes, of course' said *** 'you must decide for yourself'. And the world opened up for my dad and he said 'if that's how it is then I would like to be put to sleep as soon as possible'. (Belgium, Case 5, Palliative care unit, Relative)

Patients were often unable to contribute to the decision to commence continuous sedation either because of an acute exacerbation of symptoms, which is what had necessitated the use of sedation, or because they were very close to death and had already lost the capacity to participate in the decision-making. Where the physician initiated the use of sedation, the decision had generally been taken at an 
earlier phase in anticipation of the moment when suffering would become unbearable. Some health care staff, mostly in the Netherlands, pointed out that the decision to commence continuous sedation is in the end a medical decision that physicians could take only if they 'felt that it was inevitable':

In some cases $[\ldots]$ you see the patient is deteriorating and more and more medication is needed. Then a stage comes where you do talk with each other about gosh what are we going to do next? Patients do generally put that forward themselves, but it remains a medical decision that always lies with the doctor. And it may very well be that the doctor does not agree with the request of the patient, for the simple reason that there are no refractory symptoms or other cases. [...] (The Netherlands, Case 12, Community, Nurse)

In contrast, most health care staff in the UK pointed to a gradual progression without a particular moment of decision-making:

We always start in a cautious way and build up rather than starting with a high dose and completely flattening somebody at the outset, and that can sometimes be difficult. [...] The family need to know that the intention is to review regularly and to be able to give an extra dose if necessary. (UK, Case 4, Hospice, Physician)

In other situations, family members had requested the use of sedation. For example, this was the case for a 30 -year-old man with a melanoma who died in a Belgian hospital (Case 12). The patient had earlier told his wife that he wanted to die 'in his sleep', and that when he lost capacity and was suffering too much, she was to instruct the doctor to start the sedation. That is what eventually happened:

He actually said to me as well like: when you see that I am suffering too much, then you have to tell them that they should administer that. If I have to die, I rather die in my sleep he said because I do not ... That he must not feel it. (Belgium, Case 12, Hospital, Relative)

\section{Discussion and conclusion}

\section{Main findings}

This study distinguishes four stages of decision-making: the initiation phase where the issue is raised, the exchange of all necessary information, the deliberation phase in which it is decided to use continuous sedation when it becomes appropriate and the decision to begin continuous sedation. Although the overarching goal of continuous sedation at the end of life was similar in all cases, there was considerable variation in the timing and the role played by the patient in the decision-making. At one end of the spectrum, decision-making was primarily clinical and physician-driven; the physician discussed the possible use of sedation with the patient but took the final decision him/ herself. These cases were especially prevalent in the UK, where respondents reported a gradual process of sedation, from the provision of low doses of sedatives to the more rarely used continuous deep sedation. At the other end of the spectrum, the patient initiated the conversation about the use of sedation while the physician's role was predominantly limited to evaluating whether, and when, the patient's condition fulfilled the medical criteria. These cases were mostly from Belgium and the Netherlands, where patients were sometimes offered the 'choice' of sedation.

\section{Strengths and limitations}

The validity of this study was increased by deliberately sampling cases from three different care settings and three different countries using standardized criteria including a descriptive definition of the practice that was studied. In order to get a broad and detailed overview of each case, we included the recollections of physicians, nurses and relatives involved in the care of a particular person. Since preferences can change during the decision-making process, a retrospective assessment takes this possibility into account. Another strength is that we used the model of Charles et al., ${ }^{24}$ which allowed us to scrutinize the different phases of decision-making and apply them to the process of continuous sedation, which is unprecedented. Limitations to this study should also be acknowledged. Our interview data were dependent on the subjective experiences and interpretations of the respondents. There is a small risk of recall bias, although this was limited in most of the cases by limiting the time between death and the interview to 3 months.

\section{Discussion}

A theoretical framework such as that of Charles et al. ${ }^{24}$ seems useful in exploring end-of-life decision-making, showing there are several approaches to the initial decision to start continuous sedation. Decision-making in all phases could be described as being paternalistic, shared or informed, but it sometimes changed between the different phases. For example, in some cases, the physician began the process with an informative approach but eventually took charge of the final decision to begin continuous sedation. Other studies have not described the decision-making process in such detail. In our study, the possible use of continuous sedation was usually discussed with all parties and ultimately led to the consent and/or decision to use sedation if necessary. The information exchange and deliberation phases in our study closely match the three-step model for shared decision-making for clinical practice developed by Elwyn et al., ${ }^{26}$ in which they made a 
distinction between 'choice talk' (making sure that patients know that different reasonable options are available), 'option talk' (providing more detailed information about the options) and 'decision talk' (considering preferences and deciding what is best). From the results of this study, it is possible to distinguish two types of decision, the decision about whether to use sedation and the decision about when to start sedation. In both types, respondents placed high value on the patient's perspective, respecting their wishes, giving them explicit information about the implications and obtaining their consent. ${ }^{27}$ However, this is far from always the case. A recent Belgian population-based death certificate study showed that the decision to use continuous sedation was in $16.2 \%$ of all cases made without a request from or the consent of the person who was dying or their family. ${ }^{17}$

Although clinical guidelines aim to support physicians in their decision-making and to promote best practice (e.g. the EAPC guideline for palliative sedation strongly encourages physicians to address end-of-life care preferences with all patients at risk of dying prior to sedation and to obtain their consent ${ }^{12,14,15}$ ), they rarely state the extent to which patient preferences should be taken into account, and how to deal with a patient's request for sedation. They do stress, however, the need for clinical indications for the use of sedation; in cases where this is the refractoriness of symptoms, a medical assessment by a clinical expert is required. ${ }^{12}$ Some guidelines and frameworks, like the Dutch and Belgian ones, add to this that continuous sedation can only be used in the context of unbearable suffering, judged primarily by the patient him or herself, which was often reflected in the Belgian and Dutch cases in our study. Belgian and Dutch respondents placed emphasis on the importance of responding to the patient's request for relief of suffering, provided that the clinical conditions were fulfilled. In both countries, patients were sometimes provided with the choice between sedation and euthanasia (which is legal, provided due care criteria are met). Thus, although respondents frequently used terms related to key indications for continuous sedation, and the decision to begin it was guided mainly by the clinical condition of the patient, it can be hypothesized that interviewees in all three countries expressed views that may corresponded to medico-cultural and societal perspectives on the practice of sedation. Different concepts of what sedation should be used for and how it should be practiced may have framed the ways in which a patient's preferences were elicited and the roles they were given in the decision-making process. Thus, the focus of decision-making seems to shift from the physician-centred medical criterion (refractoriness) in the UK to a more patient-centred perspective in Belgium and the Netherlands, where more emphasis is on the unbearableness of symptoms experienced by patients. ${ }^{28}$ It could be argued that in countries where euthanasia or physicianassisted suicide (PAS) are legal, open discussion of these and other ethically difficult end-of-life issues ${ }^{28,29}$ allow patients, their relatives and their physicians to be more open about discussing palliative sedation. ${ }^{30}$ Future research should further develop the evidence base for the role of legal and cultural context on end-of-life decisionmaking and should further focus on the effectiveness of sedation to ease refractory symptoms at the end of life.

\section{Conclusion}

Decision-making about continuous sedation goes through four stages and the involvement of the patient varies. Different conceptions of what sedation should be used for and how it should be practiced may have affected the role patients were given in the decision-making process. In order to be sensitive to a patient's individual preferences while at the same time acknowledging the potential sensitivity of raising the issue of continuous sedation until death with people who are dying, we recommend building into clinical practice opportunities to regularly discuss with them their goals and preferences regarding future medical care and treatment.

\section{Acknowledgements}

The authors thank the physicians, nurses and relatives who gave their time to be interviewed in this study. The authors further thank Jane Ruthven for providing assistance with language editing. Collaborators: The research on which this article is based is linked to a larger project, the UNBIASED study (UK Netherlands Belgium International Sedation Study), which is a collaboration between research teams in the UK, Belgium and the Netherlands. All authors and members of the UNBIASED consortium were involved in the study concept, design and interpretation of data. The following are members of the UNBIASED study: Julia Addington-Hall (University of Southampton, Southampton, UK), Livia Anquinet (Vrije Universiteit Brussel, Brussels, Belgium), Jayne Brown (De Montfort University, Leicester, UK), Sophie Bruinsma (Erasmus MC, Rotterdam, The Netherlands), Luc Deliens (Ghent University, Ghent, Belgium and Vrije Universiteit Brussel, Brussels, Belgium), Nigel Mathers (the University of Sheffield, Sheffield, UK), Freddy Mortier (Ghent University, Ghent, Belgium), Sheila Payne (Lancaster University, Lancaster, UK), Kasper Raus (Ghent University, Ghent, Belgium), Judith Rietjens (Erasmus MC, Rotterdam, The Netherlands and Vrije Universiteit Brussel, Brussels, Belgium), Clive Seale (Brunel University, Uxbridge, UK), Jane Seymour (University of Sheffield, Sheffield, UK), W. Henry Smithson (the University of Sheffield, Sheffield, UK), Sigrid Sterckx (Ghent University, Ghent, Belgium and Department of Philosophy and Moral Sciences, Vrije Universiteit Brussel, Brussels, Belgium), Rien Janssens (VU University Medical Centre, Amsterdam, The Netherlands) and Agnes van der Heide (Erasmus MC, Rotterdam, The Netherlands). 


\section{Declaration of conflicting interests}

The author(s) declared no potential conflicts of interest with respect to the research, authorship and/or publication of this article.

\section{Funding}

The author(s) disclosed receipt of the following financial support for the research, authorship and/or publication of this article: The study was funded by The Economic and Social Research Council (UK) (grant no: RES-062-23-2078), the Research Foundation Flanders (BE), the Flemish Cancer Association (BE), the Research Council of Ghent University (BE), the Netherlands Organization for Scientific Research (NL) and the Netherlands Organization for Health Research and Development (NL). Lenzo Robijn is a Pre-Doctoral Fellow of the Research Foundation Flanders (FWO). None of these funders played any role in the study design, collection, analysis or interpretation of data, or in the drafting of this article.

\section{ORCID iD}

Lenzo Robijn (iD https://orcid.org/0000-0001-7020-7638

\section{References}

1. Seymour JE, French J and Richardson E. Dying matters: let's talk about it. BMJ 2010; 341: c4860.

2. Bélanger E, Rodríguez C, Groleau D, et al. Patient participation in palliative care decisions: an ethnographic discourse analysis. Int J Qual Stud Health Well-being 2016; 11(1): 32438 .

3. Walczak A, Butow PN, Bu S, et al. A systematic review of evidence for end-of-life communication interventions: who do they target, how are they structured and do they work? Patient Educ Couns 2016; 99: 3-16.

4. Sandsdalen T, Hov R, Høye S, et al. Patients' preferences in palliative care: a systematic mixed studies review. Palliat Med 2015; 29(5): 399-419.

5. Härter M. Policy and practice developments in the implementation of shared decision making: an international perspective. Z Evid Fortbild Qual Gesundhwes 2011; 105: 229-233.

6. Chewning B, Bylund CL, Shah B, et al. Patient preferences for shared decisions: a systematic review. Patient Educ Couns 2012; 86(1): 9-18.

7. Pardon K, Deschepper R, Vander Stichele R, et al. Are patients' preferences for information and participation in medical decision-making being met? Interview study with lung cancer patients. Palliat Med 2011; 25(1): 62-70.

8. Raus K, Sterckx S and Mortier F. Continuous deep sedation at the end of life and the 'natural death' hypothesis. Bioethics 2012; 26(6): 329-336.

9. ten Have $\mathrm{H}$ and Welie JVM. Palliative sedation versus euthanasia: an ethical assessment. J Pain Symptom Manage 2014; 47(1): 123-136.

10. Radha Krishna LK. Addressing the concerns surrounding continuous deep sedation in Singapore and southeast Asia: a palliative care approach. J Bioeth Inq 2015; 12(3): 461-75.
11. Van Der Heide A, Van Delden JJM and OnwuteakaPhilipsen BD. End-of-Life Decisions in the Netherlands over 25 years. N Engl J Med 2017; 377(5): 492-494.

12. Cherny NI and Radbruch L. European Association for Palliative Care (EAPC) recommended framework for the use of sedation in palliative care. Palliat Med 2009; 23(7): 581-593.

13. Papavasiliou E, Payne S, Brearley S, et al. Continuous sedation (CS) until death: mapping the literature by bibliometric analysis. J Pain Symptom Manage 2013; 45(6): 1073-1082.e10.

14. Schildmann E and Schildmann J. Palliative sedation therapy: a systematic literature review and critical appraisal of available guidance on indication and decision making. $J$ Palliat Med 2014; 17(5): 601-611.

15. Abarshi E, Rietjens J, Robijn L, et al. International variations in clinical practice guidelines for palliative sedation: a systematic review. BMJ Support Palliat Care 2017; 7: 223-229.

16. Bruinsma S, Rietjens J and Van Der Heide A. Continuous sedation until death: state of the art. In: Sterckx S, Raus $\mathrm{K}$ and Mortier F (eds) Continuous sedation at the end of life: ethical, clinical, and legal perspectives. Cambridge: Cambridge University Press, 2013: 29-46.

17. Robijn L, Cohen J, Rietjens J, et al. Trends in continuous deep sedation until death between 2007 and 2013: a repeated nationwide survey. PLOS ONE 2016; 11: 0158188.

18. Seymour J, Rietjens J, Brown J, et al. The perspectives of clinical staff and bereaved informal care-givers on the use of continuous sedation until death for cancer patients: the study protocol of the UNBIASED study. BMC Palliat Care 2011; 10(1): 5 .

19. Seymour J, Rietjens J, Bruinsma S, et al. Using continuous sedation until death for cancer patients: a qualitative interview study of physicians' and nurses' practice in three European countries. Palliat Med 2014; 29(1): 48-59.

20. Anquinet L, Rietjens J, Van Der Heide A, et al. Physicians' experiences and perspectives regarding the use of continuous sedation until death for cancer patients in the context of psychological and existential suffering at the end of life. Psychooncology 2014; 23(5): 539-546.

21. Raus K, Brown J, Seale C, et al. Continuous sedation until death: the everyday moral reasoning of physicians, nurses and family caregivers in the UK, The Netherlands and Belgium. BMC Med Ethics 2014; 15: 14.

22. Seale C, Raus K, Bruinsma S, et al. The language of sedation in end-of-life care: the ethical reasoning of care providers in three countries. Health 2015; 19: 339-354.

23. Robijn L, Chambaere K, Raus K, et al. Reasons for continuous sedation until death in cancer patients: a qualitative interview study. Eur J Cancer Care 2017; 26: 12405.

24. Charles C, Gafni A and Whelan T. Decision-making in the physician-patient encounter: revisiting the shared treatment decision-making model. Soc Sci Med 1999; 49(5): 651-661.

25. Tong A, Sainsbury P and Craig J. Consolidated criteria for reporting qualitative research (COREQ): a 32-item checklist for interviews and focus groups. Int $J$ Qual Health Care 2007; 19(6): 349-357.

26. Elwyn G, Frosch D, Thomson R, et al. Shared decision making: a model for clinical practice. J Gen Intern Med 2012; 27(10): 1361-1367. 
27. Morita T, Hirai K and Okazaki Y. Preferences for palliative sedation therapy in the Japanese general population. $J$ Palliat Med 2002; 5(3): 375-385.

28. Raus K, Chambaere K and Sterckx S. Controversies surrounding continuous deep sedation at the end of life: the parliamentary and societal debates in France. BMC Med Ethics 2016; 17(1): 36.
29. Rietjens J, Voorhees JR, Van Der Heide A, et al. Approaches to suffering at the end of life: the use of sedation in the USA and Netherlands. J Med Ethics 2014; 40(4): 235-240.

30. Van Den Block L, Deschepper R, Bilsen J, et al. Euthanasia and other end of life decisions and care provided in final threemonths of life: nationwide retrospective study in Belgium. BMJ 2009; 339: b2772. 